\title{
INTEREACE
}

Sociologias, Porto Alegre, ano 11, no 22, jul./dez. 2009, p. 352-369

\section{"O país do futebol" mediatizado: mídia e Copa do M undo no Brasil}

ÉDSON GASTAIDO

\section{Resumo}

Este trabalho analisa o discurso midiático relativo à Copa do M undo no Brasil. Em uma revisão crítica acerca da constituição social dos "meios de comunicação de massa", discuto o processo pelo qual a mídia atua na sociedade, a partir da noção de "mediação". A partir de dados sobre a audiência e foco temático na televisão brasileira durante a Copa do M undo de 1998, analiso o papel desempenhado pela mídia na construção social do interesse pela Copa do M undo no Brasil. Sem pretender negar a legitimidade do interesse social pelo futebol no Brasil, destaco, entretanto, a participação da mídia neste processo.

Palavras-chave: Copa do M undo (futebol). Mídia. Cultura brasileira.

\footnotetext{
* Professor-Adjunto no Programa de Pós-Graduação em Ciências Sociais da U nisinos, Doutor em Multimeios (Unicamp, 2000), com Pós-Doutorado em Sociologia na Universidade de Manchester (Inglaterra, 2001).
} 


\section{Introdução}

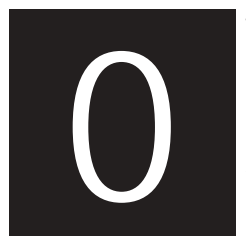

futebol no Brasil é hoje (e tem sido nos últimos cinquenta anos) uma atividade de enorme importância social, cujas consequências transcendem as linhas do campo de jogo, tornando-se mesmo questões de Estado. O s valores e número de pessoas envolvidas com este esporte chegam ambos à casa dos milhões. Milionárias também são as cifras ostentadas pelo mercado midiático. Assim como o futebol, a mídia possui uma importância social que supera largamente a dimensão do "reclame" e dos segundos em que produtos são anunciados e notícias são veiculadas. 0 dinheiro proveniente da veiculação dos anúncios sustenta toda a mídia: cada emissora de rádio, jornal, revista ou rede de televisão "comerciais" depende, para sua sobrevivência no mercado, da chamada "verba publicitária". A par deste papel de "mola-mestra" do sistema da mídia, a publicidade ainda exerce uma enorme influência na cultura contemporânea, não apenas no Brasil, mas em todo o mundo capitalista. Este artigo busca integrar estes dois domínios, relacionando o discurso midiático ao momento máximo do futebol mundial. Dessa forma, acredito que o estudo das representações presentes no cruzamento desses dois eixos de tamanha importância na sociedade brasileira possa servir como uma via de acesso ao entendimento da lógica subjacente à relação entre a dimensão social do esporte e o sistema capitalista no qual este esporte se insere.

Este artigo tem por objetivo analisar a relação entre a "mídia" (os chamados "meios de comunicação de massa") e o evento esportivo "Copa do Mundo", campeonato mundial de seleções nacionais de futebol, que desempenha um papel de extraordinária importância social no Brasil.

Acredito que, embora não determine ou condicione comportamentos ou ações sociais, a mídia certamente atua como um fator de poderosa influência no campo social. Na medida em que o discurso da mídia articu- 
la determinad os significados aos fatos enquanto oculta outros, é construída nesse discurso uma determinada "definição de realidade", que, dada a imensa difusão social de seus veículos, tem grande possibilidade de tornarse (ou "manter-se") hegemônica, colaborando assim de modo ativo na manutenção de uma dada relação de forças no interior da sociedade. Considero que problematizar o que parece evidente é uma maneira de não tomar o que é de fato socialmente "construído" (como a representação mediatizada da "realidade") por "dado" da natureza.

\section{Considerações sobre a mídia}

O termo "mídia" deriva de um aportuguesamento da pronúncia em inglês do termo latino media. Em latim, media é a forma plural de medium, "meio". Em termos do senso comum, se entende por "mídia" os "meios de comunicação de massa", versão em português da expressão mass media, ou seja, os "veículos" de comunicação, tomados como dimensão tecnológica, que, a partir da produção centralizada, veiculam seus produtos de modo "massificado", isto é, a um público numeroso e indistinto, sem levar em conta a individualidade de cada um dos participantes deste público (geralmente referido pelo termo "audiência"). Exemplos de "mídia", neste sentido, são a televisão, o rádio, o jornal, os outdoors, etc.

Não se pode, entretanto, reduzir a complexa noção de mídia a esse único aspecto. A tecnologia empregada para comunicar massivamente é, sem dúvida, um aspecto importante da noção de mídia, mas não é o único. Como entidade complexa e multidimensional, a mídia também tem uma dimensão social, manifesta estruturalmente em sua institucionalização. A tecnologia necessária à veiculação dos produtos da mídia não existe isolada na sociedade, ele se insere na sua estrutura através de instituições, como indústrias (que fornecem equipamentos e tecnologia), governos (que 
regulam as relações entre mídia e sociedade), universidades (que fornecem quadros profissionais para as instituições), além das próprias empresas de comunicação, que operam (no Brasil) sob concessão do governo, utilizando equipamentos e profissionais oriundos de outras instituições, inserindo-se assim de modo complexo na estrutura institucional da sociedade.

U ma outra dimensão da mídia que deve ser levada em conta é a condição de "bens culturais" dos seus produtos, constituindo uma "cultura de massa". A exemplo de outras empresas em nossa sociedade, as empresas de mídia também produzem "bens", que são vendidos como "mercadorias" de modo a gerar lucro para os proprietários. A diferença é que a mídia produz "bens" de uma outra ordem, os chamados "bens culturais", e o "produto" a ser "vendido" é o público atraído pelos bens culturais, a chamada "audiência". Esta analogia da produção de bens culturais mediatizados com a produção industrial propriamente dita levou Adorno e Horkheimer a cunharem a expressão "indústria cultural" (ADORNO, 1978, p. 287). Os produtos veiculados pela mídia utilizam linguagens e articulam significados a determinados referentes, criando representações que, ao serem veiculadas para a sociedade, tomada como "massa", ressaltam alguns significados, ocultam outros, incorporam significad os correntes em alguns grupos e os ampliam para toda a sociedade, entre outras operações, nas quais se manifesta o potencial de veiculação de ideologia através da mídia, "naturalizando" representações sociais e operando no sentido da manutenção de uma dada relação de forças no interior da sociedade.

Entretanto, a inserção da mídia na sociedade e seu "poder" ideológico no reforço a certos padrões culturais não devem ser tomados em um grau absoluto. As pessoas não são autômatos manipulados por uma única ideologia centralizadora. N este sentido, a noção de hegemonia de Gramsci (1975, p. 1638, ver também HALL, 1997) me parece um aporte teórico fundamental para explicar a maneira pela qual a mídia cumpre uma fun- 
ção ideológica. Gramsci considera que grupos sociais diferenciados lutam de muitas maneiras, seja usando a força ou a ideologia, para obter o "consenso" dos demais grupos e obter por esta via uma "ascendência" sobre os grupos subordinados, que Gramsci chama "hegemonia". Como resultante da dinâmica entre diferentes forças sociais em conflito, a hegemonia nunca é definitiva, os significados e representações estão sempre sendo rearticulados de acordo com o processo social. Na medida em que a hegemonia é conquistada através do conflito entre forças sociais pela articulação consensual dos significados, a veiculação de representações torna-se um elemento-chave neste processo, pois o poder de propor representações torna-se numa larga medida o poder de propor "definições" acerca da realidade: 0 tal "poder da mídia". Neste sentido, a mídia representa um elemento poderosamente eficaz na constituição de uma "versão dominante" na cultura de uma sociedade. Não existe determinação neste processo, mas influência. U ma influência poderosa, mas que também encontra-se ela mesma em plena luta entre diferentes ideologias, significados e versões concorrentes da realidade, competindo entre si para permanecer ou tornar-se o significado predominante, visando a hegemonia: como a sociedade na qual se insere, a mídia também é um vasto campo de lutas.

A noção de hegemonia, considerada como resultante de diferentes forças sociais em conflito, permite relacioná-la com a noção de "campo" de Bourdieu, que pode ser pensada como o terreno social onde ocorre a luta pela hegemonia no interior de grupos específicos e relativamente autônomos, como pode ser descrito o "campo da mídia". Nos termos deste autor, um "campo" é basicamente um terreno de luta "entre o novo que está entrando e que tenta forçar o direito de entrada, e o dominante que tenta defender o monopólio e excluir a concorrência" (BO U RDIEU, 1983a, p.89). Assim, a estrutura do campo é dada pela relação de força entre os agentes ou instituições em conflito pela distribuição do capital específico do campo. 0 "capital específico" pelo qual os diferentes veículos da mídia 
lutam gira em torno da obtenção de um dado estatístico: o chamado "índice de audiência". Em uma sociedade capitalista como a nossa, o verdadeiro "produto" que a mídia "vende" para obter lucro não é o "bem cultural" em si, maso "público" atraído pelo bem cultural veiculado, vendido aos anunciantes publicitários sob o nome de "audiência".

Segundo Grossberg, Wartella e W hitney (1998, p.208ss), em sentido estrito, a "audiência" não existe, a não ser como idealização. 0 termo "audiência" é utilizado pelos produtores da mídia e profissionais relacionados significando o "grupo" de pessoas que recebe um mesmo produto de mídia. Tal "grupo" não é um grupo, no sentido estrito do termo, mas um mero somatório de indivíduos. A noção de "audiência" nada maisé do que uma construção social, uma representação, que a partir de seu emprego permite relacionar produção e consumo dos produtos da mídia. Para estes autores, há duas maneiras básicas segundo as quais as audiências são construídas e funcionam como mercados: audiência como consumidora e audiência como mercadoria.

Para os produtores da mídia, a audiência representa, como consumidora, a possibilidade de existência da produção de mercadorias no sistema capitalista, pois uma vez produzidas, as mercadorias devem ser consumidas para que o sistema funcione. Como ressalta Haug (1997, p. 35), o chamado "encalhe" é o grande risco corrido pelo capitalista, que deve ser evitado de todas as formas, já que o lucro (objetivo do capital) só será obtido se e quando as mercadorias produzidas forem consumidas:

A ameaça de um encalhe é uma pedra no sapato do capital-mercadoria personificado pelo capitalista. A existência do encalhe significa a morte econômica do capital fixado em forma de mercadoria.

$\mathrm{Na}$ sociedade de consumo, o mercado publicitário associa a constituição de identidades para cada segmento de público consumidor a partir do consumo de determinados produtos, presentes no cotidiano publicitá- 
rio da mídia. A mídia é ao mesmo tempo parte de qualquer "estilo de vida" e uma das maneiras pelas quais tais "estilos de vida" são produzidos e promovidos. A mídia reforça o poder do mercado sobre a identidade, mesmo que ela própria produza as mesmas identidades que situam as pessoas no mercado como consumidoras.

A mídia, além de produzir a audiência como mercado para as mensagens de persuasão do consumo de mercadorias, dá a ela também uma dimensão de mercadoria, "vendendo" a audiência que construiu para os anunciantes (vendendo por um preço altíssimo, diga-se de passagem), seja em termos de sua qualidade ou de sua quantidade, mensuráveis através de "pesquisas" levadas a efeito por "institutos de pesquisa de opinião", como o lbope, por exemplo. Relacionando o potencial de mercado para anúncios publicitários com a qualidade dos programas veiculados, o "índice de audiência" tornou-se a moeda corrente na determinação do valor dos diferentes programas e veículos, principalmente para a televisão.

A propósito das mudanças culturais ocorridas no Brasil com a crescente participação na sociedade dos meios de comunicação de massa, a partir de meados dos anos 1960, Renato O rtiz (1991, p.160-165) assinala a paulatina transformação histórica do significado do termo "popular", em função do progressivo crescimento de uma "cultura de massa" no país. "Popular" foi deixando de significar algo "relativo a, ou próprio do povo", associado às manifestações folclóricas, num sentido mais conservador, ou de "próprio das classes subalternas", num sentido mais político e reformista, para assumir cada vez mais o significado de "consumido em grande escala". Esta articulação de sentido, subordinando a noção de "popular" à lógica do mercado de consumo, despolitiza o termo, na medida em que se considera o "consumo" como a categoria definitiva para o estabelecimento da relevância dos produtos culturais de massa.

Assim, por esta via transversa, o "popular", ou melhor, a "popularidade" manifesta no consumo acaba sendo o princípio motor da cultura de 
massa. M eio século depois de Adorno e Horkheimer afirmarem a transformação do "povo" em "massa" pela indústria cultural, parece que o "público" acaba determinando os rumos da própria veiculação dessa indústria. Será? Acredito que não, na medida que a representação deste "público", transformado em "audiência", ainda é feita de modo massificado, privado de individualidade e reduzido a um mero "índice" estatístico. 0 que mudou, no meu entender, foi a origem do poder: do Estado totalitário e centralizador nazista ao qual se referiam Adorno e Horkheimer, com seu sinistro "Ministério da Propaganda", para uma economia de mercado globalizante e transnacional, que aos poucos vai ocupando os espaços cedidos pelo Estado nacional. Ao poder do mercado, pouco importam posicionamentos individuais ou dissidências políticas: a categoria "consumo" passou a ser o paradigma de uma nova ordem social, que busca a máxima eficiência mercadológica. Parafraseando o famoso verso de Fernando Brant, o mercado (e seus produtos, anúncios e verbas publicitárias), assim como 0 artista, "tem de ir aonde o povo está". A presença do "povo", indicada pelo "índice de audiência", faz com que cada programa ou veículo tenha uma determinada valorização no mercado publicitário. Desta forma, muito mais do que "determinar" o que quer que seja, o papel da "audiência" no mercado de consumo parece ser o de "caça", sendo alvejada pelos anúncios. Aliás, não é outro o sentido da expressão publicitária "público-alvo".

\section{M ídia, mediação e a Copa do M undo no Brasil}

A mídia se relaciona com cada pessoa componente da "audiência" através de um processo social chamado de mediação. Grossberg, Wartella e W hitney (1998, p.14-15) assinalam quatro diferentes sentidos para este termo. Em uma primeira acepção, mais próxima do senso comum, o termo "mediar" tem um significado de "ocupar uma posição intermediária" 
entre duas partes. $\mathrm{Na}$ doutrina católica, este termo refere-se ao papel dos santos e da Virgem Maria junto a Deus, mediando (isto é, "intercedendo") às demandas dos homens perante a divindade. Em diplomacia, chama-se "mediação" o papel de um diplomata que busca negociar uma solução de consenso entre duas partes em conflito. U ma segunda acepção contrasta o "mediado" com o "imediato" (ou seja, o "real"), como na diferença entre o "mundo da TV" e o "mundo real". Um terceiro sentido de mediação compreende ambos os sentidos anteriores, entendendo a mediação como a operação cognitiva realizada entre o sujeito individual e a realidade, "um espaço feito de experiência, interpretação e significado". Estesautores assinalam ainda uma quarta acepção, a da relação formal necessária para se estabelecer um circuito de comunicação. Assim, uma definição complexa de mediação compreende todos estes sentidos, todos eles explicam uma parte da ação exercida pela mídia ao mediar o acesso à noção que constrói da realidade.

A abordagem dos diferentes esportes pela mídia é paradigmática desta noção de um acesso mediado à "realidade". Como ressalta U mberto Eco (1984, p. 220-226), existem vários níveis de apropriação da atividade esportiva: o esporte em si, "jogado em primeira pessoa", diferente de um esporte "elevado ao quadrado", que é o espetáculo esportivo. o esporte tornado espetáculo engendra um esporte "elevado ao cubo", que é o discurso sobre o esporte assistido, o discurso da imprensa esportiva. Eco ainda fala de um esporte elevado "à enésima potência", que é o discurso sobre a imprensa esportiva, como no caso dos "comentaristas" das páginas esportivas dos jornais. M ediações sucessivas, interpretações sobrepostas, metadiscursos: a mídia se apropria dos eventos e media o acesso ao acontecido. Edileuza Soares (1994, p.56-57) conta uma história que caracteriza particularmente esta apropriação/construção do "fato" pela mídia. No início dos anos 1960, quando a seleção brasileira disputou uma partida na Argélia, um radialista destacado para narrar o evento não dispunha de fio 
suficiente para chegar com seu microfone até o campo, não podendo ver o jogo que teria de narrar. Inventou então um estratagema: o ex-jogador Leônidas, então comentarista de sua emissora, ficava à beira do gramado, e corria até o local onde ficava o locutor para avisar quando acontecia um gol, e quem fora 0 artilheiro. Enquanto isso, o locutor narrava para os brasileiros do outro lado do Atlântico uma partida imaginária, na qual inseria subitamente as jogadas que conduziam aos gols anunciados pelo colega.

O pitoresco exemplo evidencia uma característica dos eventos veiculados na mídia: o evento passa por "real", mas é uma construção do enunciador, uma representação. Evidentemente, a veiculação pretende ser (e se afirma) "fiel aos fatos", mas mesmo uma transmissão de televisão ao vivo, em cores, via satélite é, em si, uma representação. Como ressalta Mauro Betti (1997, p. 33-34), sob o ponto de vista da televisão, o jogo acontece somente onde está a bola. Na transmissão de TV, ninguém tem a visão global do espaço de jogo que o espectador presente ao estádio tem. No início das transmissões de jogos de futebol pela televisão, uma única câmara fixa acompanhava de longe as jogadas. Atualmente, mesmo com as dezenas de diferentes câmaras, fixas e móveis, espalhadas pelo campo salientando diversos aspectos do jogo, ainda continua a existir esta construção narrativa, esta meta-representação do evento esportivo. Asimagens que vão ao ar são escolhidas conforme uma codificação própria do veículo (por exemplo, replays de um gol sob diversos ângulos). Carmen Rial (2003) apresenta uma detalhada análise desta "retórica televisiva" aplicada à transmissão de jogos de futebol. U m exemplo interessante em que esta (em geral) eficaz "ilusão de realidade" foi posta em evidência ocorreu na Copa de 1998, quando o jogador brasileiro Júnior Baiano cometeu pênalti no atacante norueguês Tore Flo, no jogo Brasil x Noruega, quando a partida, então empatada, chegava a seu final. As câmaras mostravam, como de praxe, a bola em jogo na intermediária, quando o árbitro apitou 
e correu para a marca do pênalti. Nenhuma das dezenas de câmaras de TV acessíveis à televisão brasileira captou a falta dentro da área. Rekdal cobrou e fez o gol da vitória da N oruega, que se classificou para as oitavasde-final, enquanto os locutores e comentaristas brasileiros bradavam unanimemente contra o "roubo" praticado pelo árbitro. No dia seguinte, alguns jogadores da seleção já admitiam ter havido a falta, embora vários articulistas nos jornais insistissem no erro do árbitro. Dois dias depois, uma imagem obtida de uma câmara exclusiva da televisão norueguesa evidenciava o puxão na camiseta sofrido pelo jogador norueguês: a imprensa aproveitou a imagem exclusiva para fazer de seu mea culpa coletivo mais uma notícia, entre tantas outras.

Se com referência à imagem ao vivo já ocorre este processo de articulação de significado, ele ainda é mais evidente quando se levam em conta a narração e os comentários acerca do jogo, tanto na transmissão de TV e rádio quanto nos jornais do dia seguinte. É evidente que não é "privilégio" do futebol ter significados construídos pela mídia. Ela opera esta mediação como regra, construindo uma "noção de realidade" própria, que evidencia determinados fatos sob determinados enfoques, em detrimento de outros. 0 interesse social pelo futebol no Brasil durante a Copa é apropriado pela mídia, que, em princípio, atende a uma "demanda social" pré-existente, produzindo peças de comunicação e criando um circuito de produção e consumo motivado pelo evento em curso, no qual se inserem, além da cobertura dos jogos, cadernos especiais nos jornais e revistas, longas matérias nos telejornais, programas diversos com a temática da Copa, anúncios publicitários, etc, colaborando de modo ativo para definir a realidade nos termos ideológicos da representação do Brasil como "o país do futebol".

A Copa do M undo é um fato social de enorme importância na cultura brasileira contemporânea, e cujo acesso está estreitamente vinculado a seu caráter mediatizado. Desde as primeiras transmissões internacionais 
de jogos de futebol por rádio, nos anos 1950, a cobertura dos jogos do Brasil na Copa do Mundo tem sido fenômeno de audiência. 0 grande interesse dos brasileiros pelo futebol, catalisado pela participação da seleção na Copa já levou à criação de mecanismos curiosos (e engenhosos) para "capturar a audiência", vencendo os concorrentes e valorizando perante os anunciantes o preço de seu tempo de veiculação. Por exemplo, durante a Copa de 1962, no Chile, os videotapes dos jogos do Brasil só conseguiam ser transmitidos no país dois dias depois dos jogos. U ma emissora de rádio de São Paulo, então, instalou na Praça da Sé, no centro da cidade, um enorme painel em formato de campo de futebol coberto de lâmpadas, com alto-falantes transmitindo os jogos do Brasil. O slocutores da emissora eram instruídos a deixar sempre claro em suas narrações a posição da bola no campo, de modo que, em São Paulo, um operador acendia a lâmpada correspondente ao deslocamento da bola no gramado do Chile. Segundo Edileusa Soares, o engenhoso mecanismo atraiu multidões para acompanhar os jogos "ao vivo", e garantiu a conquista da audiência para a emissora naquela Copa.

$\mathrm{Na}$ Copa de 1998, a concentração-recorde de audiência não foi diferente. A soma da porcentagem de aparelhos ligados nas emissoras que transmitiram os jogos teve uma média de mais de $94 \%$, tendo atingido 96\% no jogo Brasil x Marrocos, no dia 16 de junho.

Analisando a tabela com os dados da audiência na Copa de 1998, salta aos olhos o total domínio da Rede Globo sobre suas concorrentes na disputa pela audiência nesta Copa, ficando com uma média de mais de $73 \%$ dos aparelhos ligados. Dados mais completos sobre a audiência dos jogos do Brasil na Copa, distribuídos por emissora, estão na tabela a seguir.

0 fato da partida final ter apresentado o menor número de apareIhos ligados de todo o evento pode ser explicado por ter havido uma concentração do número de torcedores para cada aparelho. 0 jogo do Brasil na Copa do M undo é um momento ritual, que deve ser compartilhado em 
grupo, ainda mais se for em um domingo e se a partida decidir a Copa. Após a vitória sobre a Holanda, nas semifinais, o ufanismo tomou conta da mídia, influenciando multidões de torcedores rumo ao mais desbragado patriotismo.

Tabela 1. Audiência na Copa do M undo, por emissora. (fonte: Ibope)

\begin{tabular}{|c|c|c|c|c|c|c|}
\hline $\begin{array}{c}\text { JOGOS } \\
\text { (data e hora) }\end{array}$ & $\begin{array}{c}\text { TOTAL } \\
\text { Ligados }\end{array}$ & $\begin{array}{c}\text { Band } \\
\text { IA/PA }\end{array}$ & $\begin{array}{c}\text { Globo } \\
\text { IA/PA }\end{array}$ & $\begin{array}{c}\text { M anchete } \\
\text { IA/PA }\end{array}$ & $\begin{array}{c}\text { Record } \\
\text { IA/PA }\end{array}$ & $\begin{array}{c}\text { SBT } \\
\text { IA/PA }\end{array}$ \\
\hline Brasil x Escócia (10/6, 12h30) & 73 & $5 / 7$ & $54 / 74$ & $1 / 1$ & $3 / 4$ & $7 / 9$ \\
Brasil x M arrocos $(16 / 6,16 \mathrm{~h})$ & 74 & $7 / 10$ & $55 / 75$ & $1 / 1$ & $3 / 4$ & $4 / 6$ \\
Brasil x N oruega $(23 / 6,16 \mathrm{~h})$ & 77 & $7 / 9$ & $55 / 71$ & $* / *$ & $5 / 6$ & $4 / 6$ \\
Brasil x Chile (27/6, 16h) & 75 & $7 / 10$ & $55 / 73$ & $* / *$ & $3 / 4$ & $5 / 6$ \\
Brasil x Dinamarca (3/7, 16h) & 74 & $7 / 9$ & $56 / 75$ & $1 / 1$ & $3 / 4$ & $4 / 6$ \\
Brasil x Holanda (7/7, 16h) & 77 & $8 / 10$ & $57 / 73$ & $1 / 1$ & $2 / 3$ & $5 / 7$ \\
Brasil x França (12/7, 16h) & 70 & $7 / 10$ & $50 / 72$ & $1 / 1$ & $3 / 5$ & $4 / 6$ \\
\hline
\end{tabular}

Praça: Grande São Paulo

Universo: 4.174 .000 domicílios com TV

IA: Índice de Audiência (\%)

PA: Participação na Audiência (\% do Total de Ligados)

$*$ : menos que $0,5 \%$

Ao começar a coleta de dados para minha tese de doutoramento sobre a publicidade durante a Copa do M undo (GASTALDO, 2000), trazia como experiência pessoal de outras Copas a impressão de uma "saturação" da mídia com o tema "Copa do M undo". Creditava este fato à massiva veiculação de anúncios publicitários referentes ao tema em toda a mídia. Ao selecionar os anúncios nos diversos veículos, entretanto, fiquei surpreso em notar que, de modo geral, menos da metade dos anúncios veiculados em televisão e jornais referem-se à Copa, e menos ainda nas revistas, contrariando minha impressão inicial de que só se falava disso na publicidade. De fato, o universo dos anúncios publicitários é extraordinariamente vasto, tanto pela diversidade de veículos, agências e anunciantes, quanto pelo volume de anúncios veiculados, para que um único tema, por 
importante que seja, domine o trabalho produzido por esta comunidade discursiva tão heterogênea. No entanto, durante a Copa, a já conhecida sensação de saturação da mídia com o tema persistia. Um dia, vendo 0 "Jornal Nacional", da Rede Globo, percebi a enorme disparidade entre o tempo dedicado à Copa e o tempo dedicado a outros assuntos. Mesmo não sendo diretamente o tema que estava pesquisando, eu havia gravado vários telejornais de diversas emissoras, visando a coleta dos anúncios veiculados em seus intervalos comerciais. Assim, cotejando telejornais e anúncios publicitários, verifiquei a relação entre o tempo dedicado a matérias referentes à Copa e a outros assuntos em alguns telejornais e também nos anúncios publicitários veiculados nos seus intervalos comerciais.

Alguns exemplos deixam esta correlação bastante clara. No dia 27 de junho, em que o Brasil venceu o Chile por 4 a 1, o tempo de notícias dedicado à Copa foi de $88 \%$ do total do noticiário, correspondendo a 26 minutose 30 segundos, contra pouco mais de 3 minutos dedicados a outros assuntos, enquanto os anúncios publicitários veiculados no mesmo programa dedicaram 2 minutos e 30 à Copa, contra 6 minutos dedicados a outros temas, uma relação de $30 \%$ contra $70 \%$. No dia em que o Brasil venceu a semifinal contra a Holanda nos pênaltis, a diferença foi ainda maior: dos41 minutose meio do total de notícias do mais famoso telejornal do país, 39 minutos foram dedicados à cobertura do jogo e seus bastidores, configurando 94\% do tempo total, enquanto que os anúncios publicitários referiram a Copa do M undo em torno de $30 \%$ do tempo total de publicidade. Os dois minutos e meio restantes do telejornal foram dedicados à previsão do tempo. Entretanto, os jornais deste dia mostraram diversos fatos relevantes: invasões de terra, motins em presídios, etc, que não foram sequer mencionados.

No dia em que o Brasil perdeu para a Noruega, 23 de junho de 1998, coincidentemente faleceu o cantor Leandro, da dupla "Leandro e Leonardo", o que acabou sendo o principal "tema" do "Jornal Nacional" 
daquele dia, tendo consumido quase o dobro do tempo dedicado à Copa (afinal, o Brasil tinha perdido, mesmo...).

Neste dia, Leandro e a Copa consumiram $96 \%$ do tempo do telejornal. O s $4 \%$ restantes (exatos um minuto e trinta segundos) foram utilizados na previsão do tempo, ou seja: neste dia, nada mais aconteceu no Brasil ou no mundo (segundo o Jornal Nacional, evidentemente).

Alguns comentários podem ser feitos a respeito dos dados acima. Em primeiro lugar, é evidente que o telejornalismo satura muito mais a mídia com a temática da Copa do que os anúncios publicitários. Em boa parte, isso se deve ao fato de as matérias serem veiculadas no mesmo dia, no calor dosacontecimentos, enquanto que os filmes publicitários têm sua veiculação agendada muito tempo antes. No caso da Copa, as agências de publicidade não fazem a menor idéia se o Brasil vai ou não ser classificado para a fase seguinte. Só se tem certeza de que o Brasil disputará os jogos da primeira fase. M uitos anunciantes procuram acompanhar o curso dos eventos enviando diferentes anúncios para veiculação, com instruções para veicular um ou outro anúncio, em caso de vitória ou derrota. Além disso, o poder de definição de realidade do telejornal é imensamente maior do que o dos anúncios, cujo conteúdo simbólico e intencionalidade são mais evidentes.

O jornalismo (e o telejornalismo em particular) estipula, segundo Charaudeau (1983, p. 101), dois "contratos enunciativos": um "contrato de autenticidade", segundo o qual os eventos relatad os devem ser "fiéis" à realidade (e, em caso de crônicas ou opiniões, devem ser "objetivas") e um "contrato de seriedade", uma espécie de "contrato moral" que liga o "sujeito informador" (o jornalista) a uma obrigação de transmissão das informações. Eis o porquê, segundo este autor, do nome do enunciador desaparecer atrás da maioria das notícias dos jornais (ou telejornais), sob a figura de um enunciador coletivo ou institucional, já que todos eles, supostamente fiéis a estes contratos, tornam-se desprovidos de subjetividade. É a assim chamada "neutralidade jornalística". 
Assim, pode ser percebido que, a par da importância social da Copa do M undo para os brasileiros, existe a apropriação deste evento pela mídia, em especial pelo jornalismo, que, se não "inventa" este interesse social, pelo menos o "aumenta", com todos os meios de que dispõe, colabora para construir uma impressão de realidade que mitifica a importância da Copa, elegendo-a como o "único" acontecimento digno de menção jornalística. Dada a mediação necessária para se ter acesso aos fatos da Copa, é do máximo interesse da mídia suscitar a maior audiência possível em torno deste evento, já que, como foi visto anteriormente, o termo "audiência" refere-se diretamente à questão do "lucro" dos veículos da mídia.

\section{Considerações finais}

Após a análise destes dados, podemos perceber que, a par de um interesse social pré-existente em torno da seleção brasileira e de sua participação na Copa do Mundo, existe toda uma "construção de interesse" por parte do discurso midiático. Esta construção opera como um "amplificador" dessa demanda social, magnificando esse interesse e tornando-o central e quase exclusivo na definição da realidade no país, colaborando para gerar fenômenos de audiência a cada jogo do Brasil na competição. Afinal, audiências recordes equivalem diretamente a valorizações recordes de cada segundo veiculado.

Este interesse é construído principalmente pelo discurso jornalístico, e de modo especial pelo telejornalismo, que utiliza seu poder de "definição da realidade" para potencializar qualquer notícia, por pequena que seja, em torno do tema "Copa do M undo". 0 discurso publicitário evidentemente acompanha a tendência em voga, mas de modo surpreendentemente discreto, em relação à dedicação quase exclusiva do telejornalismo. Em parte, isso se deve à possibilidade do discurso jornalístico de "entrar 
no ar" ao vivo, quase instantaneamente, enquanto uma peça publicitária precisa de tempo para ser criada, aprovada, produzida e veiculada, e mesmo a veiculação deve ser agendada com bastante antecedência. Tal diferença de timing favorece o discurso jornalístico na referência a algo tão imprevisível quanto um jogo de futebol. Principalmente se for um jogo da seleção brasileira em uma Copa do Mundo. A realidade definida nestes termos (e as relações de poder que esta realidade representa) parece imutável, e no que depender do discurso da mídia, assim será. Afinal, como disse um locutor em off da Rede Globo, em um VT veiculado minutos após a derrota na final da Copa de 1998, em um tom algo profético, algo assustador: "Seremos sempre o país do futebol!!!"

The country of football" in the media: the relationship between the media and the FIFA World Cup in Brazil

\section{Abstract}

This paper examines the media discourse on the World Cup in Brazil. In a critical review of the social formation of the "mass media", it discusses the way in which the media operates in society, through the concept of "mediation". Considering the data on the audience and the thematic focus on Brazilian television during the World Cup of 1998, the article analyzes the role of media in the development of the interest for the World Cup in Brazil. Without denying the legitimacy of the social concern for football in Brazil, the author emphasizes the participation of the media in this process.

Keywords: FIFA World Cup. Media. Brazilian culture. 


\section{Referências}

AD O RN O, Theodor W. A Indústria cultural. In: CO HN, G (org.) Comunicação e indústria cultural. São Paulo: Companhia Editora Nacional, 1978.

BETTI, Mauro. Violência em campo - dinheiro, mídia e transgressão às regras no futebol espetáculo. Ijuí: Editora U nijuí, 1997.

BOU RDIEU, Pierre. Q uestões de Sociologia. Rio de Janeiro: Marco Zero, 1983.

BU CI-GLU CKSM AN N, Christine. Gramsci e o Estado. Rio de Janeiro: Paz e Terra, 1980.

CHARAUDEAU, Patrick. Langage et discours - eléments de semiolinguistique. Paris: Hachette, 1983.

ECO, U mberto. A Falação esportiva. In: Viagem na irrealidade cotidiana. Rio de Janeiro: Nova Fronteira, 1984.

GASTALDO, Édison. A nação e o anúncio - a representação do 'brasileiro' na publicidade da Copa do M undo. 2000. Tese (D outorado em M ultimeios). Instituto de Artes/U nicamp, Campinas,

GRAMSCI, Antonio. Q uaderni del Carcere Vol. III. Torino: Giulio Einaudi editore, 1975.

GRO SSBERG, L.; WARTELLA, E.; WHITNEY, D. MediaMaking - mass media in a popular culture. London: Sage, 1998.

HALL, Stuart. The Work of Representation. In: Representation - cultural; representations and signifying practices. London: Sage, 1997.

HAUG, Wolfgang F. Crítica da estética da mercadoria. São Paulo: Ed. Unesp, 1997.

O RTIZ, Renato. A moderna tradição brasileira. São Paulo: Brasiliense, 1991.

RIAL, Carmen. Futebol e mídia: a retórica televisiva e suas implicações na identidade nacional, de gênero e religiosa. Antropolítica, Niterói, UFF, n.14, jan-jul 2003, p. 61-80.

SO ARES, Edileuza. A bola no ar - o rádio esportivo em São Paulo. São Paulo: Summus, 1994. 